\title{
Matriz de referência como instrumento de apoio ao professor na condução do ensino de mecânica quântica para a licenciatura em física
}

\author{
Reference matrix as a teacher support tool in conducting the teaching \\ of quantum mechanics for a degree in physics
}

\author{
Rafaelle Da Silva Souza"1®, Ileana M. Greca ${ }^{2} @$ Elder Teixeira $^{3}$, Indianara Silva ${ }^{3}$ \\ ${ }^{1}$ Universidade Federal da Bahia, Instituto de Física, Salvador, BA, Brasil. \\ ${ }^{2}$ Univerdad de Burgos, Facultad de Educación, Departamento de Didáticas Específicas, Burgos, Spain. \\ ${ }^{3}$ Universidade Estadual de Feira de Santana, Departamento de Física, Feira de Santana, BA, Brasil.
}

\begin{abstract}
Recebido em 27 de janeiro de 2021. Revisado em 10 de outubro de 2021. Aceito em 09 de novembro de 2021.
Neste trabalho investigou-se como tem sido o processo de formação de professores de física na área de mecânica quântica (MQ) no Brasil. Para tanto, analisaram-se documentos que guiam os processos formativos no país, tais como as Diretrizes Curriculares Nacionais (DCN) e fontes bibliográficas que abordam o tema. Após análise desses documentos, foi apresentada uma Matriz de Referência (MR) a fim de tornar-se um instrumento de apoio ao professor na condução do ensino de MQ. Acredita-se ser possível articular propostas curriculares/cursos de MQ com o enfoque na história e filosofia da ciência que explicitem os conteúdos por meio de uma contextualização diretamente relacionada com o desenvolvimento e avanço da teoria quântica levando os estudantes a refletir sobre como ensiná-la em sua futura prática docente. Feita uma ponte com as componentes curriculares presentes nos cursos de licenciatura em física das instituições do país na área de MQ, concluímos que as relações entre a MQ, licenciatura em física e o processo formativo permeiam, majoritariamente, os conteúdos da velha teoria quântica. No entanto, para uma formação mais eficaz nessa área, sugerem-se que os componentes curriculares se aproximem da MQ moderna de modo contextualizado. A MR representa uma possibilidade de vislumbrar caminhos para a necessária mudança.
\end{abstract}

Palavras-chave: Mecânica Quântica; Licenciatura em Física; Matriz de Referência.

This work investigated how the process of training physics teachers in the area of quantum mechanics (QM) in Brazil has been. To this end, documents that guide the educational processes in the country were analyzed, such as the National Curriculum Guidelines (NCG) and bibliographic sources that address the theme. After analyzing these documents, a Reference Matrix (RM) was presented in order to become an instrument to support the teacher in conducting the teaching of QM. It is believed that it is possible to articulate curricular proposals/courses of QM with the focus on the history and philosophy of science that explain the contents through a contextualization directly related to the development and advancement of quantum theory leading students to reflect on how to teach was his future teaching practice. Having made a bridge with the curricular components present in the undergraduate courses in physics of the institutions of the country in the area of QM, we conclude that the relations between the QM, degree in physics and the training process permeate, mostly the contents of the old quantum theory. However, for a more effective training in this area, it is suggested that the curricular components approach the modern QM in a contextualized way. The RM represents a possibility to glimpse paths to the necessary change.

Keywords: Quantum Mechanics; Degree in Physics; Reference Matrix.

\section{Introdução}

A formação de professores de física no Brasil é regida por Diretrizes Curriculares Nacionais (DCN) que preconizam a prática docente na educação básica [1, 2]. A relação entre a teoria e prática implica em desenvolver no futuro professor a capacidade de mobilizar conhecimentos, habilidades e atitudes para lidar com situações,

\footnotetext{
*Endereço de correspondência: rafaellesouza2@yahoo.com.br
}

problemas e dilemas da vida profissional, sua certificação expressa legitimação social de pessoas que passam a ser reconhecidas como capazes de atuar na carreira docente com tratamento interdisciplinar 3]. Além disso, temse incentivos a relacionar os saberes epistemológicos apreendidos e as experiências vivenciadas no processo de formação docente [4].

Assume-se que o licenciado em física tem conhecimento dos processos de construção da física e a utiliza para resolver situações e problemas em sua prática 
docente. No entanto, desconsidera-se o que acontece quando no cotidiano esse saber é confrontado com as diversas formas de saber existentes. Então, que conhecimento esse licenciado recebe na graduação, que utiliza efetivamente em sua prática? Que novas posições ou estratégias poderiam ser adotadas no curso de licenciatura em física para que refletisse em melhores resultados na prática docente? Como aproximar as discussões teóricas observadas na literatura específica da sala de aula de modo a serem acionadas pelos professores subsidiando diferentes práticas pedagógicas?

Tudo isso torna a formação de professores de física o fio condutor dessa pesquisa. Concorda-se com Moreira [5], é preciso pensar em como ensinar, é preciso dar atenção à didática específica, à transposição didática, a como abordar a física de modo a despertar o interesse, a intencionalidade, a predisposição dos alunos e, assim, tornar a aprendizagem significativa. Esses desafios implicam em "mudar o currículo e o ensino na graduação em Física de modo que tenha mais física, porém de uma perspectiva contemporânea, conceitual, epistemológica e de transposição didática" [5, p. 79]. O contexto formativo e as atuais mudanças para formação do professor de física no Brasil são discutidos com maiores detalhes no Apêndice A, ver o Material Suplementar.

Nesse contexto, a presente investigação tem como objeto de estudo o currículo de mecânica quântica (MQ) para a formação inicial de professores de física. Esse recorte justifica-se pela existência de vários desafios postos ao tratá-la em sala de aula. A literatura específica, que discute o processo de ensino-aprendizagem desse campo de conhecimento, revela que, apesar de crescente o número de pesquisas, pouco tem sido modificado na realidade dos cursos de MQ [6-10].

Segundo Brasil [1], qualquer que seja a área de atuação do formando (licenciatura ou bacharelado), ele deve em geral: "ser um profissional que, apoiado em conhecimentos sólidos e atualizados em física, deve ser capaz de abordar e tratar problemas novos e tradicionais e deve estar sempre preocupado em buscar novas formas do saber e do fazer científico ou tecnológico". Portanto, a MQ faz parte dos conhecimentos que merecem atenção. Como dito, esse campo de conhecimento tem sido bastante explorado. Observa-se que há, predominantemente, uma abordagem formal restrita a certos aspectos fundamentais que mantém o escopo da velha teoria quântica adotando a interpretação de Copenhague. Entretanto, essa forma tem resultado em inúmeros desafios. Então, propõe-se elaborar uma nova abordagem mais adequada aos anseios da formação inicial.

Esse estudo resulta na elaboração de uma proposta de Matriz de Referência (MR) que sinaliza uma estrutura básica de conhecimento da MQ a ser construído por professores de física em formação inicial. O currículo deve necessariamente dialogar com a literatura agregando os argumentos de que o ensino de MQ deve explorar as componentes históricas, filosóficas, sociais e culturais da ciência, dando ênfase às potencialidades de sua utilização nas aulas [11-18. Portanto, esse trabalho concentra-se nos aspectos ligados à abordagem da MQ na formação inicial de modo a discutir os componentes curriculares por considerar que é preciso repensá-los.

A literatura tem mostrado a necessidade de reflexão sobre os objetivos do processo de ensino-aprendizagem adequados à realidade atual em contexto de alterações para adequação à BNCC, entendendo que o conhecimento de conteúdo e conhecimento pedagógico são indissociáveis, "a qual precisa ir muito além do momento de estágio obrigatório." [4, p. 4]. Então, será traçado caminhos que aproxime dos estudantes o conteúdo da teoria quântica com olhar no fazer pedagógico. Assim, a construção da MR, como instrumento de apoio pedagógico aos docentes, poderá auxiliar no planejamento de cursos sobre a MQ a fim de atingir os objetivos educacionais esperados para a formação inicial, bem como traçar metas para potencializar sua condução em sala de aula.

Assume-se, como um dos primeiros passos para se repensar as estruturas de componentes curriculares, a construção de um panorama geral dos conteúdos de MQ presentes nos cursos de licenciatura em física das instituições de ensino superior (IES) do Brasil para estabelecer os termos em que o ensino se distingue (e inova). Nesse sentido, buscou-se observar se as IES têm aderido em seus currículos novas propostas didáticas. Foram apresentadas algumas das considerações e percursos construídos para a elaboração da referida MR.

Essa proposta não se sobrepõe a outras, é uma dentre várias propostas plausíveis e interessantes e pode ser útil para qualquer outro contexto de formação de professores de física. A MR estabelecida, com pesquisa documental e bibliográfica, é um exemplo de como vislumbrar possibilidades com vistas à melhoria nos processos formativos. Selecionaram-se os conteúdos e os descritores mais mencionados em documentos oficiais e na literatura específica, de maior interesse para os futuros professores e com maior frequência de complexidade e prioridade dadas pelos docentes. Os conteúdos contemplados pela matriz consideram não apenas as diretrizes dos documentos oficiais, mas também outras visões, tais como as dos pesquisadores da área, destacando os novos marcos e critérios nesta área específica que reflete a necessidade de um novo raciocínio pedagógico para a formação docente [1, 4, 19].

\section{O ensino de Mecânica Quântica}

Historicamente, a MQ, enquanto uma teoria cientifica formal, compreende dois momentos marcantes em sua constituição. O primeiro, entre 1900 e 1925, é configurado por ideias iniciais da teoria derivadas de resultados experimentais obtidos na transição entre os séculos 19 e 20. Tratavam-se de resultados que a física clássica, nos moldes em que ela foi configurada nos séculos 18 e 19, 
não podia explicar. Hoje, este período é conhecido como a velha teoria quântica.

São os conceitos fundamentais da teoria quântica que formam a base dos avanços subsequentes. Na sequência, tem-se a formulação da equação de Schrödinger, além do trabalho de vários outros físicos como Heisenberg, Born, Dirac, Von Neumann que surgiram durante todo o primeiro quarto do século 20. Na década de 20, Louis de Broglie afirma que é possível atribuir às partículas uma propriedade ondulatória e são desenvolvidos os formalismos de Schrödinger (mecânica ondulatória) e Heisenberg (baseado na álgebra matricial) da teoria quântica. Ambos os formalismos estruturam a MQ como um arcabouço teórico que substitui e amplia o âmbito de validade das leis de movimento que, a partir de então, são consideradas inadequadas para descrever o comportamento das entidades microscópicas. Contudo, foi na década de 30 que a MQ se estabeleceu formalmente e continua em ascensão - o que configura a MQ moderna.

Após os anos efervescentes, que serviram de pano de fundo para o desenvolvimento (1900-1922) e formulação (1923-1928), veio o período de legitimação, a partir da década de 1930, da teoria quântica pela capacidade de explicar uma gama de fenômenos cada vez mais amplos, com interpretações conceituais e filosóficas seguindo um passo constante [20. Nesse momento, as questões epistemológicas e filosóficas correlatas são relegadas para segundo plano. As discussões sobre os fundamentos e interpretações ficaram restritas a pequenos grupos. Até que em 1964, com o trabalho de John Bell, recoloca-se as questões de fundamento num novo patamar, no qual podiam ser investigadas também experimentalmente [2123. Este período, caracteriza-se pela retomada das discussões interpretativas e conjecturais da MQ [24].

Entre as interpretações, destacou-se a de Copenhagen, fruto de um longo processo dialógico dentro da comunidade científica e filosófica. Seu surgimento envolve questões sobre o determinismo, o caráter probabilístico da natureza, a realidade do objeto quântico, o caráter da representação, o papel do observador e do ato de medida, o papel da consciência, a objetividade do conhecimento, a completeza da representação [25]. Aliada a alguns resultados experimentais, abre caminho para a constatação de uma teoria não-realista.

Ao optar pela Interpretação de Copenhagen, o professor deve, de alguma forma, valorizar os conceitos básicos que podem ser mantidos no ensino da MQ e, com o processo de ensino, diferenciá-la da física clássica. Um bom exemplo refere-se ao conceito de trajetória. Embora sua definição conceitual seja o mesmo, na MQ tal conceito deve ser abandonado, porque não mais há sentido em se falar em trajetória no âmbito quântico. A interpretação que oficialmente dominou a física entre 1928 e 1970 foi a da complementaridade ou a "interpretação de Copenhague", também chamada de "ortodoxa" e, portanto, é resguardada sua importância no estudo da MQ [22.
No entanto, hoje em dia vive-se em uma época de pluralidade de interpretações, logo não se pode dizer que esta interpretação seja hegemônica, como o foi anteriormente. Conforme Paulo e Moreira [26, p. 432] afirmam: "a opção pela Interpretação de Copenhagen, contudo, pode não se constituir no único caminho frutífero para o ensino da MQ. Não se pode negar que outros caminhos sejam possíveis". Desse modo, outras interpretações poderão ser apresentadas aos estudantes, reconhecendo que é indispensável a aprendizagem dos conceitos básicos em uma interpretação antes de se confrontarem com outras [27. Em termos didáticos, não é surpresa as várias dificuldades relacionadas ao ensino da MQ. Um dos principais desafios relacionados aos cursos introdutórios de MQ é, portanto, encontrar uma abordagem que equilibre a introdução dos conceitos fundamentais e as questões interpretativas de seu formalismo matemático [28].

Seu ensino é comumente introduzido através da história de sua origem. Desde o final do século 19 e até as primeiras décadas do século 20, é discutida a quantização de energia de Planck para explicar o espectro de radiação do corpo negro, os fótons de luz de Einstein para explicar o efeito fotoelétrico, os níveis de energia de Bohr em seu modelo atômico para explicar espectros, a hipótese de Broglie de ondas associadas a elétrons, Schrödinger com a formulação de uma equação de onda para elétrons em órbita, a introdução de Heisenberg do princípio da incerteza e a interpretação de Born da função de onda em termos de probabilidade [29 31].

Ressalta-se que embora os níveis do modelo de Bohr sejam usados nos livros didáticos para explicar espectros atômicos, como se isso tivesse sido a motivação para a elaboração do modelo, a primeira comprovação experimental do modelo foi de Moseley - que teve papel importantíssimo na consolidação e aceitação do modelo de Bohr, sendo o primeiro dos trabalhos experimentais a confirmar as predições. A lei de Moseley apresentava resultados bastante diferentes daqueles do paradigma científico vigente. De fato, a tabela periódica que temos hoje deve muito a Moseley [32. Ou seja, ricos aspectos históricos são desconsiderados no ensino. Discutir historicamente a comprovação da lei de Moseley possibilita compreender como se deu a revolução na distribuição dos átomos na tabela periódica, bem como motivou a descoberta de alguns elementos químicos.

Essa visão da MQ é tão difundida que vários pesquisadores consideram que muitas das dificuldades que os estudantes apresentam estão relacionadas ao seu ensino característico formal que se tem durante os cursos introdutórios [28, 33 36]. Para avanços no ensino, considerase necessário tomar algumas decisões pedagógicas. No contexto formativo das licenciaturas em física, devese ter em mente que uma abordagem primordialmente contextual-conceitual permitirá um primeiro contato com a teoria, sendo objetivo em primeira instância uma compreensão mínima da MQ. 
Os conceitos fundamentais da teoria podem ser delineados pela compreensão da dualidade onda-partícula, devendo incluir tópicos como as desigualdades de Bell e o conceito de emaranhamento quântico [37]. Desse modo, propõe-se uma estrutura acentuando reflexões qualitativas e interpretativas na tentativa de promover uma abordagem contextualizada e atual da MQ, acompanhando os avanços científicos e tecnológicos. A ideia não é excluir a velha MQ, mas evitar a restrição [38. É entendido que os conteúdos da velha MQ são necessários para entender como se chegou à equação de Schrödinger, mas que o ensino não deve ser centralizado apenas nessa parte.

Portanto, a proposta é que seja oportunizado um breve estudo da física do século 20, começando por assuntos semiclássicos seguindo com maior ênfase para os assuntos estritamente quânticos. É sugerida a ênfase em discussões nas quais o formalismo quântico se relaciona com os aspectos conceituais da teoria, sem que haja a supervalorização de procedimentos matemáticos. Segundo Johansson et al. [39], é relevante para o ensino de MQ discussões com destaque para o amplo reconhecimento de quão fundamentais foram os estudos do último século para a física, bem como o papel que tem desempenhado no cenário atual com relação aos resultados experimentais.

A motivação para essa proposição surge, apoiada na literatura da área, da necessidade de transmitir conceitos quânticos para professores de física em formação inicial e buscar diminuir as dificuldades enfrentadas no processo de ensino-aprendizagem [28, 36, 40, 43]. Espera-se promover maior significado para as aulas ajudando os estudantes a reorganizar e aprimorar seu conhecimento inicial 6, 44-47.

A proposição dessa MR abre um leque de possíveis opções para introdução de assuntos referentes à teoria quântica, nos cursos de formação em física, uma vez que capitaliza informações relativas aos aspectos conceituais, históricos e epistemológicos da teoria ao optar por propostas pedagógicas inovadoras, em que prevalecem os aspectos históricos e filosóficos concernentes às grandes controvérsias ao longo da consolidação da teoria e de seus postulados quânticos. Dessa forma, os professores se sentirão capazes de explorar a MQ, pois minimamente a compreendem [8].

\section{Percurso metodológico}

O projeto de construção da MR foi organizado em quatro etapas e apresentou delineamento qualitativo com apoio da pesquisa exploratória-descritiva [48,50]. A partir da análise das DCN e da literatura específica, foram estabelecidas as relações com o ensino de MQ e maior compreensão do problema.

$\mathrm{Na}$ etapa 1, foi feita uma análise documental e bibliográfica fundamental para levantar os elementos que irão compor a MR, utilizando-a como fonte de informação. Foram consultadas as DCN [1, 2, 4] e artigos da área de ensino da MQ [27, 28, 39, 47, [51, entre outros], e livros didáticos [31, 37, 52,55].

Na etapa 2, houve a construção da versão preliminar da matriz a partir de estudo e discussão do referencial teórico dos artigos e livros acessados pela pesquisa bibliográfica. A proposta da MR foi progressivamente reformulada, a partir dos resultados das análises da literatura, visando sistematizar os conteúdos e otimizar a operacionalização da construção do instrumento.

A seleção e delimitação dos conteúdos foi orientada pelas perguntas: (1) Para quem? - refere-se ao públicoalvo em contexto para qual está sendo desenvolvida a MR; (2) O que ensinar? - refere-se ao conhecimento a ser integrado na MR; (3) Por quê? - refere-se às razões que motivam a escolha do conhecimento; (4) Para quê? refere-se ao que se deseja desenvolver, precisamente aquilo que se pretende alcançar com o conjunto de conhecimentos selecionados; (5) Como? - refere-se às especificidades do planejamento da MR. Essas perguntas definiram o enfoque metodológico da MR. Os conteúdos foram organizados a partir do estabelecimento de eixos temáticos visando relacionar as competências e habilidades presentes nas DCN adequadas ao perfil do professor de física durante a formação inicial.

$\mathrm{Na}$ etapa 3, para a fiabilidade do instrumento foi realizada uma validação por três colaboradores à distância por via eletrônica de maneira simplificada entre profissionais efetivamente experientes na área e no campo que está se desenvolvendo o estudo. Na avaliação inicial, buscou-se a convergência de opiniões em termos de relevância e pertinência de cada descritor da matriz. Era facultado a inclusão de sugestões ao final de cada domínio, que seriam reavaliadas na etapa seguinte. Foram realizadas análises de conteúdo e críticas em torno do objetivo central por se tratar de uma MR para o ensino de MQ na formação inicial, alguns conteúdos poderiam ser postos para segundo plano e os tidos como mais relevantes permaneceriam na versão final da matriz.

$\mathrm{Na}$ etapa 4 e última, considerando o referencial teórico-metodológico aqui explicitado, optou-se por uma análise crítica dos conteúdos convencionalmente presentes nos componentes curriculares das IES do Brasil que ofertam o curso de licenciatura em física. Foi realizado um levantamento panorâmico e observou-se os conteúdos previstos, bem como os livros didáticos adotados com objetivo de fornecer subsídios para discussão e validação teórica da proposta de MR e percepção de convergências e divergências.

A coleta dos dados foi realizada no período de setembro a dezembro de 2018 e foi organizada em planilhas no Excel, possibilitando o acesso e verificação das mesmas. De posse dos dados, caracterizaram-se os componentes que compõe a amostra da pesquisa, bem como a bibliografia adotada, observando as convergências com a MR a fim de culminar em um instrumento de apoio ao professor na condução do ensino de MQ para a licenciatura com vistas a possíveis melhorias. 


\section{Resultados}

\subsection{Estrutura da Matriz de Referência}

A matriz foi elaborada para auxiliar o ensino da MQ e pode tornar-se referência em termos de expectativas básicas e essenciais ao processo de formação e, por consequência, orientar processos didático-pedagógicos e de proposição de intervenções ou tomada de decisões no âmbito do ensino. O entendimento de sua formulação permeia as perguntas levantadas, assim respondidas:

- Para quem? - elaborada para licenciatura em física;

- O que ensinar? - os conteúdos de MQ foram organizados em eixos temáticos tendo como critério contemplar, de forma extensiva, os elementos básicos para a formação do professor.

Cada eixo temático foi elencado de modo a representar o agrupamento de conhecimentos abrangidos pela MQ e tem a função de auxiliar na orientação e no planejamento do trabalho docente. Serão listados amplamente os conhecimentos da MQ para que seja possível compreender os filtros de restrição aplicados a posteriori. São estabelecidos os seguintes eixos:

Eixo temático 1 (E1) - princípios e conceitos fenomenológicos - iniciado pela introdução dos fundamentos da velha MQ (1900-1925), envolvendo os operadores e postulados quânticos até as recentes conceituações;

Eixo temático 2 (E2) - formalismo matemático e métodos de cálculos - inclui desde pré-requisitos para o estudo da MQ até a introdução da equação de Schrödinger e a mecânica matricial;

Eixo temático 3 (E3) - efeitos, experimentos e consequências - inclui desde os efeitos mais introdutórios, como o efeito fotoelétrico, até os que exigem maior conhecimento dos fundamentos quânticos como os experimentos de Aspect;

Eixo temático 4 (E4) - aplicações tecnológicas se propõe abordar os desenvolvimentos práticos da MQ. Historicamente a primeira aplicação da MQ foi o átomo de hidrogênio com o famoso modelo de Bohr, mas em decorrência de seu desenvolvimento são observadas uma gama de utilidades práticas;

Eixo temático 5 (E5) - métodos didáticos - é voltado para o estreitamento das relações entre a teoria e a prática docente. Ressalta-se que esse eixo destoa dos demais por relacionar aspectos diretamente pedagógicos. Porém, trata-se de uma relação de causa e efeito: Uma vez que está se formando futuros professores discutindo determinado conteúdo, se há reflexões sobre a futura prática docente é possível que se oportunize habilidades específicas.
Na seleção de conteúdo, realizada uma consulta a três colaboradores, percebeu-se em princípio que houve concordância em suas avaliações. Contudo, algumas ponderações foram feitas. Quanto a acréscimos: (1) inserção de pré-requisitos, sendo um deles a álgebra linear. neste caso, não no sentido de incluir mais conteúdo, mas como base de estruturação matemática da MQ; (2) inclusão de aspectos históricos e filosóficos tanto como método didático de ensino quanto de discussão para transposição didática com foco na prática docente; (3) ênfase na discussão conceitual do conteúdo. Quanto a exclusões, um aspecto foi assinalado: quais dos conteúdos levantados com base na revisão bibliográfica pareceria mais complexo para a compreensão do estudante e qual deles tinha maior prioridade para o processo de ensinoaprendizagem.

Nesse momento é tomada a decisão de advogar pela descentralização das ideias iniciais da MQ e dos conteúdos mais avançados da teoria considerando que seu ensino pode ser oportunizado em outros momentos. Por exemplo, as ideias iniciais podem ser adequadamente discutidas em componentes curriculares anteriores à MQ, como no caso da física moderna; e os conteúdos mais avançados em formação continuada. Essa consideração está em sintonia com a literatura acerca das exigências para se formar um professor de física qualificado para compreender, entre outros assuntos, conceitos da MQ. Portanto, na MR foram sinalizados os conteúdos de maior interesse e com maior correlação positiva.

- Por quê? - para melhor compreensão dos fenômenos quânticos, o ensino da MQ deve ser desenvolvido com um enfoque mais conceitual, contextual e fenomenológico. A literatura revela que a ausência de um ensino nessa perspectiva gera dificuldades no processo de formação dos estudantes e, portanto, pesquisadores da área concordam entre si que é preciso atrair mais atenção pedagógica para o desenvolvimento de diferentes práticas metodológicas [17, 42, 47, 56, 59].

Considera-se como conhecimento conceitual o conjunto de conceitos, modelos e teorias que compõem o conhecimento de MQ, o contextual como todo conteúdo que remete a um contexto social, tecnológico, ambiental ou histórico que dá sentido aos conceitos quânticos apresentados, o fenomenológico sendo as situações subatômicas não visíveis, mas que podem ser detectados, e o epistemológico, a dimensão que refere-se aos conteúdos que fazem menção a natureza da ciência ou operações que são desenvolvidas para produzir conhecimento. Portanto, torna-se necessário a referência aos contextos nos quais esses conceitos são aplicáveis, aos contextos históricos em que eles surgiram e às suas interações com outros conceitos. Essas relações possibilitam o estudante explicitar suas ideias, trabalhar com elas e refletir sobre seus significados. Esta articulação pode favorecer melhor compreensão dos conceitos científicos, tirando do estudante a impressão de que a ciência deve 
ser aprendida de forma passiva, pois ele deve participar desse processo de construção.

Para conseguir estes objetivos, concorda-se com Hadzidaki [40, 41, que uma educação científica responsável deve ir além da preparação para aprender as ideias básicas e os cálculos técnicos da MQ, mas deve ajudar os estudantes a compreender como a ciência se relaciona com toda a cultura, dando-lhes o conhecimento suficiente para participar da cultura científica quando seja necessário e oferecer-lhes a oportunidade de pensar sobre as implicações filosóficas derivadas da física moderna, questões que passam, umas e outras, por uma apropriada compreensão conceitual da MQ.

- Para quê? - o processo de ensino-aprendizagem da MQ na formação inicial tem esbarrado, entre outros obstáculos, na falta de uma compreensão conceitual, logo é importante repensar seu ensino buscando solucionar os problemas enfrentados.

Como afirmam Greca e Freire Jr. 60], parte da dificuldade com seus conceitos, que se distanciam de conceitos culturalmente compreendidos como a causalidade, o determinismo ou a localidade, é sua apresentação basicamente formalista, centrada na aprendizagem de métodos matemáticos de resolução de casos típicos, com pouca ou nenhuma discussão conceitual ou interpretacional. Portanto, considera-se que um ensino mais contextualizado apresenta maior possibilidade de compreensão da MQ e de êxitos na futura prática docente.

- Como? - não há consenso entre as abordagens para o ensino de MQ. Diferentes abordagens são possíveis, mas para não se estender nessa discussão, alinhou-se ao apresentado por Greca e Moreira [57] e Cuesta [47. Há pesquisas que não indicam essas mesmas categorias.

(1) Abordagem histórico-conceitual - propõe um modelo construtivista em que os estudantes se envolvam em atividades e situações problemas que lhes permitam conhecer alguns dos estágios históricos do surgimento de novas hipóteses e dos conceitos quânticos fundamentais;

(2) visão filosófica - considera que a MQ tem um conjunto de regras de cálculo muito acuradas, mas cuja interpretação Física ainda não está completamente compreendida, logo o estudante deve adquirir uma visão epistemológica salientando-se os aspectos conceituais;

(3) abordagem "particularista" - introduz a descrição quântica destacando o caráter corpuscular;

(4) utilização de recursos computacionais - auxiliar os estudantes a visualizar aspectos centrais do mundo microscópico;

(5) ênfase na prática experimental - propõe práticas de laboratório para trabalhar com os estudantes identificação, argumentação e explicação dos fenômenos quânticos (conceitos e natureza da ciência);

(6) utilização de resultados recentes sobre fundamentos da MQ - prioriza exemplos baseados em experimentos recentes e discussões que apontem para aspectos da MQ moderna, em oposição às abordagens que buscam semelhanças com sistemas clássicos, envolvendo o estudante com ferramentas quânticas básicas;

(7) enfoque físico/matemático - equilibrando os temas abordados entre demonstrações matemáticas simples, mas fundamentais para discussões conceituais;

(8) mudança curricular - enfatiza conteúdos mais atualizados e o uso de tecnologias de informação e comunicação, mas também dá atenção a marcos históricos e epistemológicos no desenvolvimento da física, assim como para teorias de aprendizagem.

Nossa escolha é pelo uso didático da história e filosofia da ciência (HFC). A justificativa é que o ensino de MQ pode beneficiar-se ao ser explorado o papel desempenhado pelos cientistas e suas contribuições ao longo do desenvolvimento da nova teoria, ao reunir argumentos dos trabalhos teóricos e experimentais realizados, ao discutir o enfrentamento dos obstáculos tecnológicos que dificultam seu desenvolvimento, além de priorizar a apresentação das considerações epistemológicas e ontológicas subjacentes ao objeto do conhecimento associado ao formalismo matemático, ou ainda ao discutir as controvérsias sobre as interpretações e implicações conceituais 6, 33, 61, 62.

Assim, o ensino de MQ não supervaloriza procedimentos matemáticos, mas conecta-se aos resultados experimentais, interpretativos e incluindo as contribuições dos vários físicos/estudiosos. A ênfase na discussão conceitual do conteúdo deverá ser oportunizada a partir de um tópico/exemplo concreto. Essa forma de ensino justifica-se, entre outras razões, pela tentativa de incorporar uma nova perspectiva para os conteúdos, trazendo consigo a expectativa de novas ações pedagógicas e novas abordagens nas propostas didáticas, como é o caso exemplificativo do uso didático da HFC.

Conforme esses direcionamentos e adequando-se as diretrizes essenciais para formação de professores [1, 2, 4, estabeleceu-se conformidade ao perfil profissional com as competências e habilidades para o licenciado em Física adequando-as ao ensino de MQ aqui proposto. Segundo Brasil [4], são 10 competências gerais (Quadro 1) e 12 competências específicas, estas últimas agrupadas em três dimensões (conhecimento, prática e engajamento profissionais), com descrições detalhadas de habilidades em cada uma (Quadro 2). No caso dos cursos de bacharelado e licenciatura em física, Brasil 1 apresenta 5 competências e 11 habilidades específicas (Quadro 3). Vale registrar que essa última DCN é anterior a resolução 
Quadro 1: Competências gerais docentes (BRASIL, 2019).

\section{COMPETÊNCIAS GERAIS DOCENTES}

1. Compreender e utilizar os conhecimentos historicamente construídos para poder ensinar a realidade com engajamento na aprendizagem do estudante e na sua própria aprendizagem colaborando para a construção de uma sociedade livre, justa, democrática e inclusiva.

2. Pesquisar, investigar, refletir, realizar a análise crítica, usar a criatividade e buscar soluções tecnológicas para selecionar, organizar e planejar práticas pedagógicas desafiadoras, coerentes e significativas.

3. Valorizar e incentivar as diversas manifestações artísticas e culturais, tanto locais quanto mundiais, e a participação em práticas diversificadas da produção artístico-cultural para que o estudante possa ampliar seu repertório cultural.

4. Utilizar diferentes linguagens - verbal, corporal, visual, sonora e digital - para se expressar e fazer com que o estudante amplie seu modelo de expressão ao partilhar informações, experiências, ideias e sentimentos em diferentes contextos, produzindo sentidos que levem ao entendimento mútuo.

5. Compreender, utilizar e criar tecnologias digitais de informação e comunicação de forma crítica, significativa, reflexiva e ética nas diversas práticas docentes, como recurso pedagógico e como ferramenta de formação, para comunicar, acessar e disseminar informações, produzir conhecimentos, resolver problemas e potencializar as aprendizagens.

6. Valorizar a formação permanente para o exercício profissional, buscar atualização na sua área e afins, apropriar-se de novos conhecimentos e experiências que lhe possibilitem aperfeiçoamento profissional e eficácia e fazer escolhas alinhadas ao exercício da cidadania, ao seu projeto de vida, com liberdade, autonomia, consciência crítica e responsabilidade.

7. Desenvolver argumentos com base em fatos, dados e informações científicas para formular, negociar e defender ideias, pontos de vista e decisões comuns, que respeitem e promovam os direitos humanos, a consciência socioambiental, o consumo responsável em âmbito local, regional e global, com posicionamento ético em relação ao cuidado de si mesmo, dos outros e do planeta.

8. Conhecer-se, apreciar-se e cuidar de sua saúde física e emocional, compreendendo-se na diversidade humana, reconhecendo suas emoções e as dos outros, com autocrítica e capacidade para lidar com elas, desenvolver o autoconhecimento e o autocuidado nos estudantes.

9. Exercitar a empatia, o diálogo, a resolução de conflitos e a cooperação, fazendo-se respeitar e promovendo o respeito ao outro e aos direitos humanos, com acolhimento e valorização da diversidade de indivíduos e de grupos sociais, seus saberes, identidades, culturas e potencialidades, sem preconceitos de qualquer natureza, para promover ambiente colaborativo nos locais de aprendizagem.

10. Agir e incentivar, pessoal e coletivamente, com autonomia, responsabilidade, flexibilidade, resiliência, a abertura a diferentes opiniões e concepções pedagógicas, tomando decisões com base em princípios éticos, democráticos, inclusivos, sustentáveis e solidários, para que o ambiente de aprendizagem possa refletir esses valores.

Quadro 2: Competências específicas (BRASIL, 2019).

\section{COMPETÊNCIAS ESPECÍFICAS}

\begin{tabular}{|c|c|c|}
\hline 1. Conhecimento Profissional & 2. Prática Profissional & 3. Engajamento Profissional \\
\hline $\begin{array}{l}\text { 1.1 Dominar os objetos de } \\
\text { conhecimento e saber como ensiná-los }\end{array}$ & $\begin{array}{l}2.1 \text { Planejar as ações de ensino que } \\
\text { resultem em efetivas aprendizagens }\end{array}$ & $\begin{array}{l}\text { 3.1 Comprometer-se com o próprio } \\
\text { desenvolvimento profissional }\end{array}$ \\
\hline $\begin{array}{l}\text { 1.2 Demonstrar conhecimento sobre os } \\
\text { estudantes e como eles aprendem }\end{array}$ & $\begin{array}{l}2.2 \text { Criar e saber gerir ambientes de } \\
\text { aprendizagem }\end{array}$ & $\begin{array}{l}3.2 \text { Comprometer-se com a } \\
\text { aprendizagem dos estudantes e } \\
\text { colocar em prática o princípio de } \\
\text { que todos são capazes de aprender }\end{array}$ \\
\hline 1.3 Reconhecer os contextos & $\begin{array}{l}\text { 2.3 Avaliar o desenvolvimento do } \\
\text { educando, a aprendizagem e o } \\
\text { ensino }\end{array}$ & $\begin{array}{l}\text { 3.3 Participar do Projeto } \\
\text { Pedagógico da escola e da } \\
\text { construção dos valores } \\
\text { democráticos }\end{array}$ \\
\hline $\begin{array}{l}\text { 1.4 Conhecer a estrutura e a } \\
\text { governança dos sistemas educacionais }\end{array}$ & $\begin{array}{l}\text { 2.4 Conduzir as práticas } \\
\text { pedagógicas dos objetos } \\
\text { conhecimento, competências e } \\
\text { habilidades }\end{array}$ & $\begin{array}{l}\text { 3.4 Engajar-se, profissionalmente, } \\
\text { com as famílias e com a } \\
\text { comunidade }\end{array}$ \\
\hline
\end{tabular}


Quadro 3: Competências e Habilidades para os cursos de física (BRASIL, 2001).

\begin{tabular}{ll}
\hline Competências \\
\hline C1 & $\begin{array}{l}\text { Dominar princípios gerais e fundamentos da física, estando familiarizado com suas áreas clássicas e } \\
\text { modernas }\end{array}$
\end{tabular}

C2 Descrever e explicar fenômenos naturais, processos e equipamentos tecnológicos em termos de conceitos, teorias e princípios físicos gerais

C3 Diagnosticar, formular e encaminhar a solução de problemas físicos, experimentais ou teóricos, práticos ou abstratos, fazendo uso dos instrumentos laboratoriais ou matemáticos apropriados

C4 Manter atualizada sua cultura científica geral e sua cultura técnica profissional específica

C5 Desenvolver uma ética de atuação profissional e a consequente responsabilidade social, compreendendo a ciência como conhecimento histórico, desenvolvido em diferentes contextos sócio-políticos, culturais e econômicos

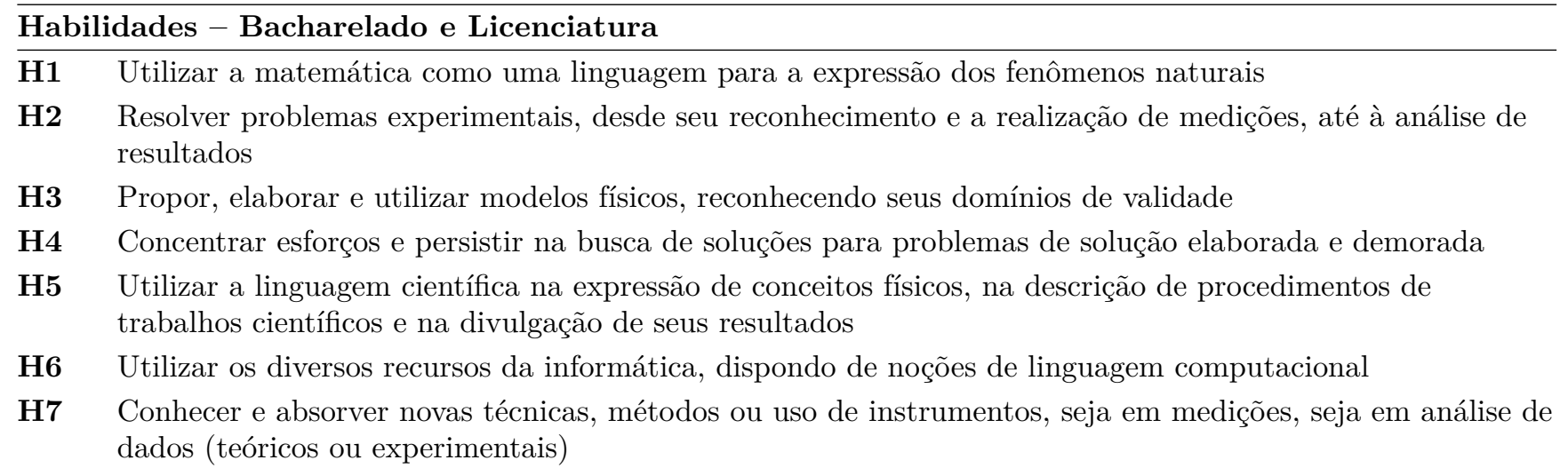

H8 Reconhecer as relações do desenvolvimento da física com outras áreas do saber, tecnologias e instâncias sociais, especialmente contemporâneas

H9 Apresentar resultados científicos em distintas formas de expressão, tais como relatórios, trabalhos para publicação, seminários e palestras

Habilidades especificas da licenciatura:

H10 O planejamento e o desenvolvimento de diferentes experiências didáticas em física, reconhecendo os elementos relevantes às estratégias adequadas

H11 A elaboração ou adaptação de materiais didáticos de diferentes naturezas, identificando seus objetivos formativos, de aprendizagem e educacionais

$\mathrm{CNE} / \mathrm{CP} \mathrm{n}^{\underline{0}}$ 2/2019, logo está passível de revisão e atualização - dar-se um primeiro passo de análise.

A relação da BNC-Formação com as diretrizes para formação do licenciado em física é estabelecida. As competências (C1, C2, .., C5) e habilidades (H1, H2, ..., H11) são distribuídas interseccionando-se com os conteúdos distribuídos por eixos temáticos $(\mathrm{E} 1, \mathrm{E} 2, \ldots$, E5) nas células dispostas no Quadro 4 As intersecções distribuídas de modo a constituírem um todo unificado com dependência mútua completa - devem necessariamente buscar alcançar o perfil profissional orientado na BNC-Formação envolvendo as três dimensões que fazem parte da competência profissional do professor: conhecimento, prática e engajamento. Essas dimensões são articuladas e interagem entre si para a compreensão da competência profissional. Desse modo, a intenção é explorar como o professor pode unir a prática de sala de aula ao compromisso com a aprendizagem dos alunos e seu desenvolvimento profissional por meio do estudo de um conteúdo específico para alcançar competências e habilidades específicas para sua profissão.

Essa estruturação está em consonância com as ideias de Silva [63]. Para ele, o currículo é resultado da seleção de um universo mais amplo de conhecimentos e saberes que irá constituí-lo. Nesse sentido, considerou-se que tais ideias devem se estender aos componentes curriculares que compõem os cursos com a intenção de contribuir para a total e plena construção da identidade dos futuros professores. A perspectiva adotada está baseada na concepção de que o ensino de MQ não pode ser realizado de forma estanque e separado dos demais elementos da MR. E reforça que na profissão docente, o conhecimento não está desvinculado da prática.

Dessa forma, uma decisão tomada para trabalhar com um conteúdo específico depende, em essência, das decisões adotadas em relação aos demais. Ressalta-se que os eixos temáticos não são estanques, pelo contrário, são abertos e estão constantemente em construção. 
Quadro 4: Matriz referência com adequação ao perfil profissional para o professor de Física.

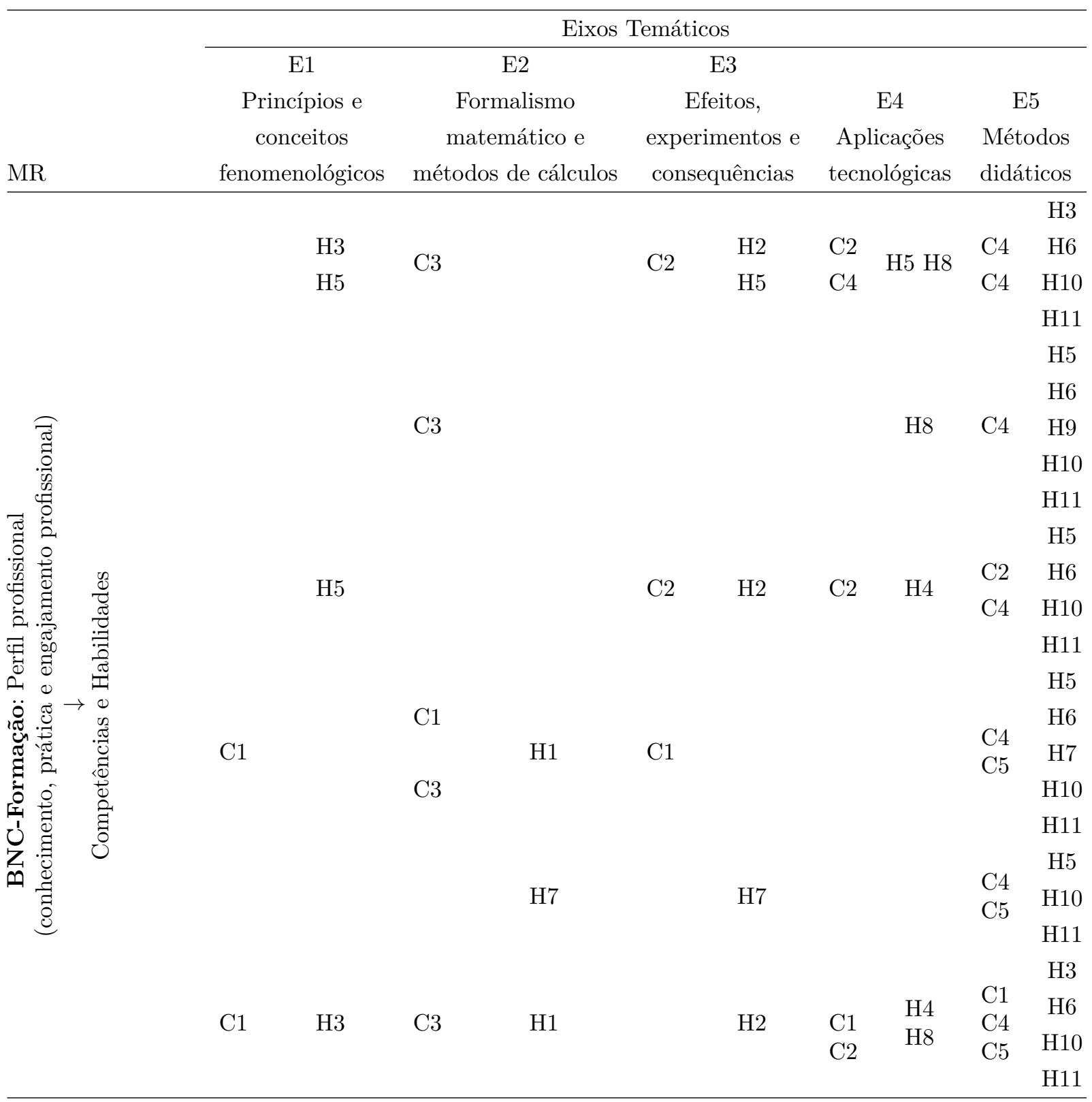

É possível discutir integradamente aspectos importantes sobre um tema escolhido, proporcionando compreensão mais ampla dos conceitos, fenômenos e consequências relacionadas. Entende-se que não é suficiente o professor ter o saber conceitual ou a capacidade transmissiva, ele precisa desenvolver o domínio relacional, a habilidade de conviver na diversidade das situações de sala de aula e estar comprometido com o seu fazer profissional. Portanto, articular as três dimensões do perfil profissional permite uma coerência entre aquilo que ensina e aquilo que o aluno [no caso, o estudante universitário] será capaz de ensinar.

O Quadro 5 a seguir, representa o instrumento elaborado para o ensino de MQ construído a partir dos estudos documental e bibliográfico realizados, sendo inseridos os tópicos de modo extensivo. Os elementos tachados (ex. Radiação do corpo negre) são os conhecimentos da MQ sugeridos a descentralização devido à motivação, segundo a literatura da área, de otimizar o ensino da teoria na licenciatura através do oferecimento de uma visão mais direta dos fenômenos da MQ moderna [28, 64].

Em sua versão final, aplicados os filtros supracitados, a MR ficou composta da articulação de quatro grandes domínios: perfil profissional; competências e habilidades; conteúdos; abordagem didática. Os domínios foram estruturados detalhadamente para compreenderem as características essenciais a serem perseguidas durante o ensino de MQ na formação inicial. Sua estrutura apresenta singularidades quando comparada com as matrizes tradicionais. A estruturação do conhecimento específico valorizando a contextualização marca uma perspectiva inovadora. 
A título de exemplificação, se um professor decide planejar uma unidade de ensino sobre o princípio da complementaridade utilizando a matriz, ele necessariamente precisará escolher caminhos para desenvolver o seu tra- balho que perpasse os demais eixos. Alguns descritores idealizados desse processo são postos no Quadro 5 Cada descritor elaborado considerou os objetivos educacionais estabelecidos para formação inicial e procurou articular

Quadro 5: Matriz de Referência.

MATRIZ DE REFERÊNCIA PARA O ENSINO DE MECÂNICA QUÂNTICA NA FORMAÇÃO INICIAL DE PROFESSORES DE FÍSICA

\begin{tabular}{ccc}
\hline Conteúdo & Indicadores & Descritores \\
\hline & EIXO TEMÁTICO 1: PRINCÍPIOS E CONCEITOS FENOMENOLÓGICOS
\end{tabular}

Radiação-de-corpo-negre
Hipótese de Planck
Quantização-da-energia
Dualidade Onda-Partícula
Princípio da Incerteza
Modelo atômice
Átomo- de Bøhr
Hipótese de Broglie
Átomo-de hidrogênie
Spin do Elétron
Limites da Física Clássica
Função de onda (Eq. de Schrödinger)
Princípio da complementaridade
Princípio da correspondência
Superposição de estados
Estados quânticos
Argumento de EPR
Problema da Medição
Observáveis
Caráter probabilístico
Não-localidade
Redução do pacote de onda
Postulados da Mecânica Quântica
Princípio de Pauli

$\mathrm{Pq}$

$\mathrm{Pb}$

$P_{e}$

$\mathrm{Pd}$

$\mathrm{Pe}$

Pf

$\mathrm{Pg}$

$\mathrm{Ph}$

$\mathrm{Pi}$

$\mathrm{Pj}$

$\mathrm{Pl}$

$\mathrm{Pm}$

$\mathrm{Pn}$

Po

$\mathrm{Pp}$

$\mathrm{Pq}$

$\operatorname{Pr}$

Ps

$\mathrm{Pt}$

$\mathrm{Pu}$

$\mathrm{PV}_{\mathrm{V}}$

$\mathrm{Px}$

$\mathrm{Pz}$

$\mathrm{Pl}$
Esse eixo é voltado para o ensino dos princípios e conceitos da MQ ordenando uma série de discussões com o objetivo de promover o conhecimento dos aspectos que fundamentam a teoria, bem como estabelecer suas inter-relações com os demais eixos a fim de contextualizá-los e significá-los.

\section{EXEMPLOS}

Pl e Pz. Estabelecer os limites da Física Clássica ao discutir os postulados da MQ. Pm. Apresentar a interpretação padrão de Copenhague e como uma função de onda (ou vetor de estado) descreve um único sistema em um único instante.

Ps-Pz. Enunciar o problema da medição; estabelecer modelos teóricos e resultados experimentais com objetivo comum de entender o mundo físico; discutir a natureza quântica a partir da superposição e emaranhamento e suas propriedades independentes por meio do processo de medição; compreender o conceito de medição no domínio quântico.

\section{EIXO TEMÁTICO 2: FORMALISMO MATEMÁTICO E MÉTODOS DE CÁLCULOS}

Noções de Álgebra linear (pré-requisito)

Notação de Dirac

$\mathrm{Fa}$

$\mathrm{Fb}$

Espaço de Hilbert

$\mathrm{Fc}$

Eq. de Schrödinger dependente/ind.do tempo

Fd

Eq. de Schrödinger tridimensional

Valores esperados e operadores

Potenciais unidi. independentes do tempo

Potenciais em três dimensẽes

Oscilador harmônico

Autofunções e autovalores

Estados estacionários

Momento angular

Formulação matricial

Evolução temporal de um sistema quântice

Método variacional e aproximação (WKB)

Teoria de perturbaçã

Teoria do espalhamento

Noçẽes de Estatística Quântica
Neste eixo, espera-se o uso do formalismo matemático enfatizando a priori as relações entre conceitos físicos. Embora seja importante exercitar sua operabilidade, se espera que o nível de exposição auxilie o estudo da MQ no sentido de compreensão dos fenômenos.

\section{EXEMPLOS}

Fc. Pz. Introduzir uma formulação do espaço de Hilbert para a teoria probabilística e, partir desta construir os postulados da MQ.

Fb. Introduzir os espaços vetoriais complexos através da notação de Dirac, representando um estado físico da MQ contendo todas as informações daquele estado.

(Continued) 
Quadro 5: Continued

\section{EIXO TEMÁTICO 3: EFEITOS, EXPERIMENTOS E CONSEQUÊNCIAS}

$\begin{array}{ll}\text { Efeito fotoelétrice } & \text { Ea } \\ \text { Efeito Compton } & \text { Eb } \\ \text { Experimento de Taylor } & \mathrm{Ec} \\ \text { Experimento Franck-Hertz } & \mathrm{Ed} \\ \text { Experimento Davisson-Germer } & \mathrm{Ee} \\ \text { Experimento de Thomson (difração de } & \mathrm{Ef} \\ \text { elétrons) e Jönson (dupla fenda c/elétrons) } & \\ \text { Experimento Stern-Gerlach } & \mathrm{Eg} \\ \text { Emaranhamento quântico } & \mathrm{Eh} \\ \text { Interferômetro de Mach-Zehnder } & \mathrm{Ei} \\ \text { Efeito Zeeman } & \mathrm{Ej} \\ \text { Efeito Stark } & \mathrm{El} \\ \text { Efeito Túnel } & \mathrm{En} \\ \text { Experimentos de Aspect } & \mathrm{En} \\ \text { Interpretações da Mecânica Quântica } & \mathrm{Eo}\end{array}$

A contextualização dos princípios e conceitos

Eat

$\mathrm{Eb}$

Ec

Ed

Ee

Ef

$\mathrm{Eg}$

Eh

$\mathrm{Ei}$

$\mathrm{Ej}$

$\mathrm{El}$

Em

En

Eo pautados nas experiências criam as condições necessárias para compreensão dos fenômenos quânticos; mas essa contextualização só tem sentido físico com o formalismo que permite ler tal fenômeno.

\section{EXEMPLOS}

Eh. Compreender o fenômeno tomando inicialmente o contexto no qual se deram as reflexões teóricas propostas por Einstein, Podolsky e Rosen (1935).

Ei, En. Analisar o fenômeno da interferência quântica sob a luz das principais interpretações da MQ.

\section{EIXO TEMÁTICO 4: APLICAÇÕES TECNOLÓGICAS}

Teletransporte quântico

Computação quântica

Criptografia quântica

Dispositivos microprocessados

Nanotecnologia*

Tomografia computadorizada*

Ressonância magnética*

Laser*

* Ver não como uma aplicação MQ, mas destacar o limite clássico
Aa Os usos e tecnologias relacionados a MQ

$\mathrm{Ab}$ decorrentes dos fundamentos quânticos

Ac trata-se de uma importante estratégia para

Ad auxiliar no desenvolvimento de competências

Ae para a formação do professor.

\section{Af EXEMPLOS}

Ag Aa-Ah. Estabelecer os limites da Física

Ah Clássica discutindo como a MQ contribui(u) para o avanço da ciência.

Aa-Ac, Pr. Explorar o argumento de EPR associado aos possíveis desenvolvimentos tecnológicos.

\section{EIXO TEMÁTICO 5: MÉTODOS DIDÁTICOS}

Aspectos históricos

Aspectos filosóficos

Aspetos metodológicos para transposição didática
$\mathrm{Ma}$

$\mathrm{Mb}$

$\mathrm{Mc}$
Uma das capacidades que o licenciando deve desenvolver é a percepção de como abordar tais tópicos em sua prática docente. Sugere-se uma abordagem que utilize os vários enfoques da MQ, vislumbrando possibilidades de introdução do tema no ensino médio. Aqui, exemplificamos o uso da História e Filosofia da Ciência como estratégia de ensino.

Nota: os indicadores, a fim de diferenciá-los são a junção da letra inicial de especificação do eixo com a sequenciação das letras do alfabeto. Ou seja, $P$ (E1 - Princípios) $a$ (primeiro tópico do eixo), Pa.

o processo cognitivo para a compreensão do estudante sobre o conhecimento em discussão. Por esse motivo, a MR pode ter sua dinâmica alterada ou adequada pelo professor - quando ele achar necessário - bem como poderá ser ramificada em várias intervenções didáticas ou componentes curriculares.

Para advogar a aplicabilidade desse instrumento apresenta-se dois estudos. O primeiro estudo de Silva et al. [65, no qual é analisado como estudantes ingressantes na universidade produziram sentidos sobre o paradoxo EPR a partir da leitura de fragmentos do artigo de Einstein, Podolski e Rosen (1935) em texto de divulgação científica - de acordo com a MR, esse estudo mobiliza os eixos E1, E3 e E5. Para os autores, embora a maioria dos participantes tenha relatado dificuldades na leitura, a proposta didática parece lhes ter proporcionado pequenos incrementos em sua compreensão sobre o assunto.

No segundo estudo de Souza et al. 66, realizado em contexto mais amplo, é implementado uma proposta didática com a utilização da HFC para auxiliar a aprendizagem da MQ, discutindo os conceitos de emaranhamento quântico e não-localidade na licenciatura em Física. Os autores destacam que o uso da HFC é percebido como passo importante para aprendizagem de MQ. "Os estudantes, embora tenham apresentado lacunas na compreensão conceitual, mostram-se interes- 
sados na HFC, uma vez que ela possibilita ricas trocas histórico-conceituais fundamentais para que se prossiga com aprendizagem" [66, p. 16] - são mobilizados os eixos E1, E3, E4 e E5.

Dessa forma, a MR é colocada como instrumento de apoio para orientar as intencionalidades dos professores frente aos desafios do processo de ensino-aprendizagem podendo sofrer alterações de acordo com a necessidade. Ainda, para verificar a potencialidade da MR, a partir de análise documental discutiu-se nas seções seguintes um levantamento panorâmico dos componentes curriculares de MQ dos cursos de física do Brasil, que resultam em inferências e evidências teóricas quanto a concentração de conteúdos de MQ nos currículos.

\subsection{Avaliação do perfil de ensino da MQ}

A formação inicial de professores é, sem dúvida, ainda um grande desafio a ser vencido. Nesse contexto, é importante conhecer mais de perto o processo de formação proposto nas DCN, ainda que não fique explicito quais conteúdos devem compor as matrizes curriculares [1, 2 4. As regulamentações apenas afirmam que "o núcleo comum é caracterizado por conjuntos de disciplinas relativos à física geral, matemática, física clássica, física moderna e ciência como atividade humana." [1, p. 6]. Se entende por física moderna e contemporânea: "a física desde o início do séc. XX, compreendendo conceitos de mecânica quântica, física estatística, relatividade e aplicações." [1, p. 7].

Em virtude do exposto, apresenta-se a seguir uma discussão sobre a correspondência entre os conteúdos tratados nas IES e os eixos temáticos estruturados na MR. Uma análise panorâmica e estatística dos componentes curriculares da MQ é apresentada no Apêndice B, ver o Material Suplementar.

\subsection{Eixo temático 1: princípios e conceitos feno- menológicos}

A diversidade no ensino de MQ é tamanha que mesmo tópicos frequentemente discutidos não há garantias de sua presença no currículo. No entanto, a partir dos dados expostos no Apêndice B, há uma certa tradição compartilhada no que diz respeito a ênfase em objetos dos conhecimentos pertinentes à velha $\mathrm{MQ}$ - indicadores de Pa a Pm.

É comum o ensino de tópicos mais introdutórios da MQ. Em geral, são usados para abordar a radiação térmica, mais precisamente a radiação de corpo negro (geralmente é feita uma abordagem clássica do assunto), a teoria de Planck, a quantização da energia e a discussão de fótons de luz de Einstein para explicar o efeito fotoelétrico. Os níveis de energia de Bohr são utilizados para explicar espectros atômicos, a hipótese de ondas associados com os elétrons de Broglie. Depois é introduzida a função de onda, a dualidade onda-partícula e o princípio da incerteza de Heisenberg.
Na base desses conhecimentos emanam determinadas concepções sobre a matéria que são conhecimentos chaves para a compreensão do modelo teórico da MQ. No entanto, se o currículo de MQ se limita prioritariamente ao perfil acima citado, segundo reporta a investigação de González et al. 67], os professores desenvolverão visões históricas e conceituais reducionistas e, possivelmente, com associação as ideais clássicas assinalando uma série de limitação nos processos de ensino da teoria quântica.

Além disso, muito tempo é destinado a discussão de aspectos mais introdutórios. Isso limita o tempo de estudo da MQ em seu estabelecimento formal, fins da década de 1920. O ensino desses conceitos iniciais não é somente uma grande simplificação, mas também uma imagem falsa do que realmente seja a MQ [28]. Os aspectos conceituais fundamentais da MQ moderna são, então, bastante negligenciados, enfatizando-se o ensino de uma MQ em boa parte ultrapassada e com um foco em desenvolvimentos matemáticos. $\mathrm{O}$ ensino realizado desta forma, é considerado árduo pelos estudantes em formação e não consegue estimulá-los a lecionar tópicos desta teoria na escola básica.

Outro aspecto é sobre conteúdos que contemplam os postulados da MQ e suas noções estatísticas que não são abordados efetivamente ou, quando abordados, limitam-se a estabelecer o caráter probabilístico da MQ. Considera-se importante a abordagem dos primeiros postulados da MQ e suas implicações, como por exemplo, o emaranhado quântico, os relógios atômicos e a Criptografia Quântica [68]. Além de gerar a possibilidade de compreensão da imagem quântica do mundo, auxilia na associação com os avanços tecnológicos de origem quântica, aspectos de fato relevantes para a formação docente.

\subsection{Eixo temático 2: formalismo matemático e métodos de cálculos}

A formulação da equação de onda, a interpretação em termos do momento angular, aplicações aos potenciais, suas respectivas aplicações e a notação de Dirac são os tópicos frequentes nos currículos. Porém, ensinar ideias fundamentais de MQ não deve se limitar ao caráter extremamente matemático [34, 69. As leis do movimento ondulatório de uma partícula são tratadas com a equação de onda na forma diferencial consistente com as equações de Newton e com os postulados de BroglieEinstein. Em seguida, pode-se analisar a interpretação de Born para funções de onda com estabelecimento das previsões probabilísticas (valores esperados), inserindo os métodos de operadores na MQ.

Além disso, Rocha et al. [68, apontam que em vários cursos o ensino de MQ enfatiza a resolução de problemas envolvendo equações diferenciais e com poucos aspectos relacionados aos conceitos fundamentais. É também caráter predominante dos componentes o conteúdo ser apresentado de forma dedutiva, deixando de lado seu desenvolvimento histórico. Assim, uma das causas para 
o insucesso do ensino da MQ parece residir na maneira como os conteúdos têm sido apresentados aos estudantes.

\subsection{Eixo temático 3: efeitos, experimentos e consequências}

A discussão das propriedades corpusculares e ondulatórias das partículas estão presentes também nesse eixo. Contempla-se a hipótese de Broglie, de que uma partícula material tem associada uma onda de matéria e que governa seu movimento, comprovada posteriormente com a experiência de Davisson-Germer e a de Thomson. Em seguida, chega-se à interpretação de Born sobre dualidade onda-partícula. Desse tópico, surgem as evidências que levam ao princípio da incerteza de Heisenberg e suas consequências, o que possibilitou o estudo das propriedades das ondas de matéria; mas que pouco são contextualizados.

Mesmo na literatura específica, não há consenso entre as implementações de propostas didáticas nem sobre quais as melhores escolhas para discutir os fenômenos quânticos. Abordagens com variadas estratégias didáticas (a exemplo, HFC, as tecnologias de informação e comunicação, experimentos, material didático específico) são adotadas, a depender de cada contexto e enfoque didático [27, 47, 70]. No entanto, o argumento é um só: são didaticamente eficientes em detrimento ao ensino nos moldes tradicionais.

\subsection{Eixo temático 4: aplicações tecnológicas}

Em consonância com o eixo temático 3, um melhor entendimento dos conceitos e fenômenos quânticos pode ser alcançado através da discussão da aplicabilidade da teoria decorrentes do seu desenvolvimento - utilizada como recurso motivador -, para que, quando os estudantes estiverem compreendendo os fundamentos, possam ser apresentados ao formalismo matemático. No entanto, em quase sua totalidade o ensino da MQ é desconectado desses aspectos.

Destarte, um curso de MQ deve perpassar os eixos temáticos apresentados na MR e não exigir do estudante apenas conhecimento em Física Matemática. A omissão da discussão sobre as aplicações tecnológicas dificulta a aprendizagem subsequente dos estudantes em relação aos conceitos atinentes à MQ [71. Portanto, é fundamental um ensino para além dos formalismos matemáticos.

\subsection{Eixo temático 5: métodos didáticos}

Além da aplicabilidade da MQ como critério para a introdução de seu ensino, deve-se reconhecer a relevância das implicações filosóficas e epistemológicas [72]. No entanto, estes aspectos históricos-filosóficos não são frequentes nos currículos. Esse resultado reafirma o discutido por Teixeira, Freire Jr. [73] sobre o quão têm sido ausente, nos currículos dos cursos de graduação em física no Brasil, aspectos históricos e epistemológicos da ciência, e, portanto, esse incentivo se faz necessário.

Segundo Moreira [74, mesmo estando no século 21, a física ensinada não passa do século 19. É preciso que conceitos físicos sejam discutidos nesse contexto e incentive sua compreensão incorporando as tecnologias e situações que façam sentido para os estudantes. Ressalta-se que no processo de construção da MR, foi observado que a MQ introduzida é relacionada com elementos da física clássica, considerando seus pressupostos mais básicos e formalismo matemático complexo sem discutir, ou discutindo superficialmente, o fato de que os objetos de estudo quânticos são advindos de uma natureza diversa daqueles objetos clássicos [75].

Nesse sentido, muitos problemas filosóficos e de aprendizagem emergem ao pensar no ensino da MQ como conteúdo para o ensino superior [76]. Ou seja, as abordagens tradicionais não criam condições para que os estudantes aprendam os fenômenos e princípios da MQ. É preocupante que, apesar da diversidade de tópicos apresentados na MR, se observe, em termos gerais, uma uniformidade apenas no conteúdo da velha MQ. Essas limitações podem gerar outras. Por exemplo, nenhum currículo analisado aborda os aspectos necessários para a adequada relação Teoria-Prática, e, portanto, não instruem diretamente os futuros professores para o ensino de MQ na educação básica. No entanto, uma ferramenta tão relevante quanto o conhecimento técnico é o conhecimento de um aparato teórico que permita a abordagem destes conhecimentos mais modernos no ensino médio.

Este processo é o que Yves Chevallard [77] define como transposição didática - instrumento que possibilita analisar o processo de transposição de saberes para diferentes contextos - processo fundamental de operacionalização que viabiliza as experiências de ensino e estimula a criatividade didática. A discussão sobre os métodos didáticos para ensinar a MQ é extremadamente relevante, principalmente, por ser a participação dos professores indispensável para a atualização, revisão ou reformulação curricular [78].

Dessa forma, a abordagem proposta poderá auxiliar na superação de dificuldades enfrentadas no processo de ensino-aprendizagem da MQ e no distanciamento entre ela e a aplicabilidade, bem como poderá dar lugar a uma melhor formação do professor sobre tais aspectos. Esse olhar crítico é fundamental, pois assim será possível desenvolver o processo educacional.

\subsection{Perspectivas ao ensino de MQ na formação de professores}

Algumas constatações que são apresentadas ao longo do trabalho não são novidades e já são debatidas há algum tempo (excesso de tempo dado à velha MQ, excessivo apego das instituições formadoras a livros didáticos que omitem discussão sobre fundamentos da MQ, introdução da MQ com contexto podendo ser por meio da HFC e outros). A questão é a ausência de uma maior frequência 
de práticas inovadoras na sala de aula que privilegie, por exemplo, uma perspectiva de contextualização para o ensino da MQ.

Em virtude disso, a MR apresenta um caminho para se buscar novas possibilidades de melhorias para a formação de professores de física. O processo formativo deve preparar o licenciado para as novas demandas educacionais do século 21, e no contexto apresentado, a abordagem proposta se torna um apoio importante para repensar a formação na área de $\mathrm{MQ}$ e a relação com a prática docente. A referida contextualização é pensada através da incorporação da HFC, entendendo que a articulação entre os saberes específicos dispostos nas regulamentações oficiais claramente sinaliza para a necessária reorientação das práticas e dos saberes docentes, considerando, entre outros, a atual relevância de compreender os diversos conceitos científicos e suas aplicações.

O caráter de maior confiabilidade e de validação dessa matriz se baseia na explicitação dos modos como tem se feito presente a MQ no currículo, que se valeu de uma ampla análise. Além disso, a contribuição dos colaboradores argumenta pela descentralização de alguns conteúdos que têm sido demasiadamente ensinados nacionalmente defendendo outros julgados mais importantes, sem, contudo, perder sua capacidade de expressar sinteticamente aquilo que se considera essencial e até mesmo imprescindível para se alcançar uma formação de qualidade, conforme entendido nas DCN. Argumentos apoiados também pela literatura [28].

Reconhece-se que o processo de ensino-aprendizagem é complexo. Que ensinar física é um grande desafio e que começa na formação dos professores. Não é novidade que licenciandos finalizam o curso de física com dificuldades e defasagens nas competências referentes ao domínio dos conteúdos a serem socializados (saber específico). Logo, pesquisas na área de formação docente precisam ser incentivadas.

Considerando isso, não é intenção apresentar uma generalização, bem como a MR apresentada não esgota todo conteúdo a ser trabalhado em sala de aula. Busca-se aqui lançar novas discussões nesse campo, ao nortear o que se espera do futuro professor em termos de formação inicial para atuação em nível médio, centrada das demandas oriundas da legislação e da literatura específica. Lembra-se que esse instrumento pode sofrer variações, a fim de alcançar resultados de aperfeiçoamentos metodológicos. A MR funcionará apenas como um dos instrumentos facilitadores do trabalho dos professores em sala de aula.

\section{Considerações}

A matriz foi construída com base na análise das DCN, de artigos acadêmicos sobre o ensino de MQ e livros didáticos. Os conteúdos incluídos na matriz foram selecionados por critérios voltados ao público-alvo (licenciandos) e organizados em cinco eixos temáticos. É feita a opção por uma abordagem contextualizada por meio da HFC desses conteúdos. O resultado foi validado por colaboradores e por comparativo com ementas de componentes curriculares da IES do Brasil que ofertam o curso de licenciatura em física. Assim, a ideia geral desse artigo concentra-se em desenvolver uma proposta de MR que incorpora tendências atuais para ensino de MQ, sendo esse um recurso que pode interessar aos docentes envolvidos na formação de professores de física.

A literatura aqui discutida teve a intenção de mapear a situação atual do ensino de MQ mostrando a forma multifacetada das bases curriculares e as tendências a serem seguidas para os possíveis caminhos apontados no texto. As reflexões sugerem um olhar mais apurado sobre o problema em questão: como articular conteúdos de MQ (o que ensinar, como ensinar e a partir de que parâmetros) para buscar superar deficiências enfrentadas na formação inicial.

Nessa perspectiva, o ensino de MQ surge da interrelação dos elementos da matriz, orientado pelas competências e habilidades específicas e do debate contemporâneo mais amplo, uma vez que ensinar requer tanto dispor de conhecimentos e mobilizá-los para a ação, como compreender o processo de construção do conhecimento. Torna-se fundamental investir na possibilidade de introdução de alguns desses tópicos, sobre a perspectiva apresentada e que se atente, explicitamente, para as dificuldades de interpretações dos fenômenos quânticos pelos discentes para que possibilite mobilizar no futuro professor as competências necessárias para uma efetiva formação.

De acordo com os resultados apresentados, os professores de física formados nas IES brasileiras têm, em sua maioria, estudado com bastante ênfase apenas conceitos da velha MQ; seja por limitações nos livros didáticos e/ou pouco tempo dispensado (ou ainda sua ausência) dos componentes curriculares de MQ; o processo formativo tem sido deficiente e pode resultar em dificuldades para ensinar tópicos da MQ no nível médio.

Por fim, essas considerações não apontam para um fechamento dos temas discutidos e desenvolvidos nesse artigo, no qual procuraram-se articular teoria e prática que fornecessem uma base possível para a construção de uma proposta de MR para o ensino de MQ. Pelo contrário, houve a intenção de fomentar o debate em torno da temática que se amplia como uma necessidade emergente nos dias atuais, tornando-se um desafio aos educadores; uma tentativa de transcender da teoria à prática que leve a compreensão mais efetiva da MQ. Este é um estudo introdutório, estudos posteriores auxiliarão no aprimoramento do instrumento proposto.

\section{Material suplementar}

O seguinte material suplementar está disponível online Apêndice A: A formação do professor de Física no Brasil 
Apêndice B: Análise panorâmica dos componentes curriculares da $\mathrm{MQ}$

\section{Referências}

[1] MINISTÉRIO DA EDUCAÇÃO, Diretrizes Curriculares para os Cursos de Bacharelado e Licenciatura em Física. Brasília: Parecer no CNE/CES no ${ }^{\circ}$ 1304/2001 de 03 de abril de 2001.

[2] Brasil. MINISTÉRIO DA EDUCAÇÃO, Resolução CNE/CES 9/2002. Diretrizes Curriculares Nacionais para os Cursos de Bacharelado e Licenciatura Física. Brasília: MEC, 2002.

[3] BRASIL, Base Nacional Comum Curricular (BNCC). Educação é a Base. Brasília, MEC/CONSED/UNDIME, 2018.

[4] Brasil. Ministério da Educação, Resolução CNE/CP $n^{-}$ 2, de 20 de dezembro de 2019. Diretrizes Curriculares Nacionais para a Formação Inicial de Professores para a Educação Básica e institui a Base Nacional Comum para a Formação Inicial de Professores da Educação Básica (BNC-Formação). Brasília: MEC, 2019.

[5] M.A. Moreira, Estud. av. 32, (2018).

[6] M.A. Monteiro, R. Nardi e J.B. Bastos Filho, Ciência \& Educação 15, 557 (2009).

[7] G.F. Pantoja, M.A. Moreira e V.E. Herscovitz, Revista Brasileira de Ensino de Ciência e Tecnologia 4, 1 (2011).

[8] M.A.B. Santos, A Mecânica Quântica no processo de formação de licenciandos em Física: um estudo de caso. Tese de Doutorado, Universidade Federal da Bahia, Campina Grande (2012).

[9] K. Krijtenburg-Lewerissa, H. Pol, A. Brinkman e W. van Joolingen, Phys. Rev. Phys. Educ. Res. 13, 010109 (2017).

[10] C.R. Rocha, M.A. Moreira e V.E. Herscovitz, LatinAmerican Journal of Physics Education 12, 1306 (2018).

[11] O. Freire Jr., R. Carvalho Neto, J. Rocha, M. Vasconcelos, M. Socorro e E. Anjos, em: Third International History, Philosophy and Science Teaching Conference (412-419), (Minneapolis, 1995).

[12] F. Ostermann, Revista Brasileira de Ensino de Física 21, 415 (1999).

[13] F. Ostermann e C. J. H. Cavalcante, Caderno Catarinense de Ensino de Física 16, 267 (1999).

[14] F. Ostermann e M.A. Moreira, Enseñanza de las Ciencias 18, 391 (2000a).

[15] A.C. Pinto e J. Zanetic, Caderno Catarinense de Ensino de Física, Florianópolis 16, 7 (1999).

[16] E.A. Terrazzan, Caderno Catarinense de Ensino de Física 9, 209 (1992).

[17] E.A. Terrazzan, Perspectivas para a inserção da Física Moderna na escola média. Tese de Doutorado, Universidade de São Paulo, São Paulo (1994).

[18] R.S. Souza, I.M. Greca, I. Silva e E.S. Teixeira, Revista Brasileira de Pesquisa em Educação em Ciências 20, 1363 (2021)

[19] C.W. Rosa e A.B. Rosa, Revista Iberoamericana de Educación / Revista Ibero-americana de Educação 58, 1 (2012).

[20] F. Laloë, American Journal of Physics 69, 655 (2001).
[21] O. Freire Jr., Science \& Education 12, 573 (2003).

[22] O. Freire Jr., Studies In History and Philosophy of Science Part B 37, 577 (2006).

[23] O. Freire Jr., Studies In History and Philosophy of Science Part B 40, 280 (2009).

[24] D. Bohm, Quantum theory (Dover Publications, New York, 1989).

[25] M. Beller, Quantum dialogue: the making of a revolution (University of Chicago, Chicago, 2001).

[26] I.J.C. Paulo e M.A. Moreira, Ciênc. educ. (Bauru) 17, $421(2011)$.

[27] I. M. Greca, Construindo significados em mecânica quântica: resultados de uma proposta didática aplicada a estudantes de física geral. Tese de Doutorado, Universidade Federal do Rio Grande do Sul, Porto Alegre (2000).

[28] I.M. Greca e O. Freire Jr., in: International Handbook of Research in History, Philosophy and Science Teaching, editado por M.R. Matthews (Springer, New York, 2014) v. 1, pp. 183-209.

[29] R.M. Eisberg e R. Resnick, Física quântica: átomos, moléculas, sólidos, núcleos e partículas (Campus, Rio de Janeiro, 1979).

[30] J.J. Sakurai, Modern Quantum Mechanics (Pearson Education, 1994).

[31] D. J. Griffiths, Mecânica Quântica (Pearson, São Paulo, 2011), 2 $2^{\mathrm{a}}$ ed, pp. 323-341.

[32] C.A. Santos, A. Villani, J.M.F. Bassalo, R.A. Martins, Da revolução científica à revolução tecnológica: tópicos de história da Física Moderna (UFRGS, Porto Alegre, 1998), $228 \mathrm{p}$.

[33] H. Fischler e M. Lichtfeldt, International Journal of Science Education, London 14, 181 (1992).

[34] I. D. Johnston, K. Crawford e P.R. Fletcher, Int. J. Sci. Educ. 20, 427 (1998).

[35] S.B. Mckagan, K.K. Perkins, M. Dubson, C. Malley, S. Reid, R.S. Reid Ron et al., American Journal of Physics 76, 406 (2008).

[36] I.M. Greca, O. Freire Jr., Science \& Education 12, 541 (2003).

[37] O. Pessoa Jr., Conceitos de Física Quântica (São Paulo, Editora Livraria de Física, 2003), $1^{\mathrm{a}}$ ed., v. 1.

[38] L. Dominguini, J.R. Maximiano e L. Cardoso, em: IX Seminário de Pesquisa em Educação da Região Sul (Caxias do Sul, 2012).

[39] A. Johansson, S. Andersson, M. Salminen-Karlsson e M. Elmgren, Cultural Studies of Science Education 1, 205 (2018).

[40] P. Hadzidaki, Science \& Education 17, 49 (2008a).

[41] P. Hadzidaki, Science \& Education 17, 613 (2008b).

[42] L.C. Mcdermott e E. Redish, American Journal of Physics 67, 755 (1999).

[43] S. Wuttiprom, M.D. Sharma, I.D. Johnston, R. Chitaree e C. Soankwan, International Journal of Science Education 31, 631 (2009).

[44] P. Wattanakasiwich, Model of understanding of probability in modern physics, Tese de Doutorado, Oregon State University (2005).

[45] N. Didio , A. Eryilmaz e S. Erkoç, Eurasia Journal of Mathematics, Science \& Technology Education 6, 227 (2010). 
[46] B. Akarsu, Asian Journal of Applied Sciences 4, 112 (2011).

[47] Y.J. Cuesta-Beltrán, Tecné, Episteme y Didaxis: TED 44, 147 (2018).

[48] J.W. Creswell, Projeto de pesquisa: métodos qualitativo, quantitativo e misto (Porto Alegre, Artmed, 2007).

[49] A.C. Gil, Métodos e técnicas de pesquisa social (São Paulo, Atlas, 2008), $6^{\text {a }}$ ed.

[50] R.A. Dal-Farra e P.T.C. Lopes, Nuances: estudos sobre Educação 24, 67 (2013).

[51] F. Ostermann e M.A. Moreira, Investigações em Ensino de Ciências, Porto Alegre 5, 23 (2000b).

[52] K. Gottfried e T. Yan, Quantum Mechanics (Springer, New York, 2004), $2^{\text {a }}$ ed.

[53] S. Perez, Mecânica Quântica: um curso para professores da Educação Básica (São Paulo, Livraria da Física, 2016).

[54] M. Le Bellac, Quantum Physics (Cambridge U. P., New York, 2006).

[55] M. Novais e N. Studart, Mecânica quântica básica (São Paulo, Editora Livraria da Física, 2016).

[56] T. Kallio-Tamminen, Quantum metaphysics. The role of human beings within the paradigms of classical and quantum physics. Tese de Doutorado, University of Helsinki, Helsinki (2004).

[57] I. M. Greca e M. A. Moreira, Investigação em Ensino de Ciências 6, 29 (2001).

[58] T. Lobato e I.M. Greca, Ciência \& Educação, Bauru 11, 119 (2005).

[59] A. Muller, Designing effective multimedia for physics education. Tese de Doutorado, University of Sydney, Sydney (2008).

[60] I.M. Greca e O. Freire Jr., em: O. Freire jr., O. Pessoa jr., J.L. Bromberg (Orgs.). Teoria Quântica: Estudos Históricos e Implicações Culturais (São Paulo, EDUEPB; Livraria da Física, 2011).

[61] D.G.C. Jones, Physics Education, Bristol 26, 93 (1991).

[62] F. Ostermann e T.F. Ricci, em: Simpósio Nacional de Ensino de Física, 15, 2003 (Curitiba, 2003).

[63] T.S. Silva, Documentos de Identidade: uma introdução às teorias do currículo (Autêntica, Belo Horizonte, 2005).

[64] R.A Carvalho Neto, O. Freire jr. E J.L. Silva, Investigação em Ensino de Ciências, 3, 75 (2008).

[65] A.C. Silva, M.J.P.M. Almeida, e M.L. Hallack, Caderno Brasileiro de Ensino de Física 32, 53 (2015).

[66] R.S Souza, I. Silva e E.S. Teixeira, Revista Docência do Ensino Superior 10, 1 (2020).

[67] C.V. González, Revista Eureka sobre Ensenanza y Divulgación de las Ciencias 1, 214 (2004).

[68] C.R. Rocha, M.A. Moreira e V.E. Herscovitz, Revista Brasileira de Ensino de Ciência e Tecnologia 3, 2 (2010).

[69] J. Castrillon, O. Freire Jr. e B. Rodriguez, Rev. Bras. Ensino Fís. 36, 1 (2014).

[70] M.A. Fanaro, M.E. Góndola, Enseñanza y Aprendizaje de las Ciencias 13, 272 (2018).

[71] P. Shabajee e K. Postlethwaite, School Science Review, 8151 (2000).

[72] M.A. Fanaro, M. Arlego, M.R. Otero, Caderno Brasileiro de Ensino de Física, Florianópolis 24, 233 (2007).
[73] E.S. Teixeira e O. Freire Jr., em: Atas do XVII Simpósio Nacional de Ensino de Física (São Luís, 2007).

[74] M.A. Moreira, Revista do Professor de Física. Brasília 1, 1 (2017).

[75] A. Guerra, J. Freitas, J.C. Reis e M.A. Braga, Caderno Catarinense de Ensino de Física 15, 32 (1998).

[76] I.M. Greca, M.A. Moreira e V.E. Herscovitz, Rev. Bras. Ensino Fís. 23, 444 (2001).

[77] Y. Chevallard, La transposición didáctica: del saber sabio al saber enseñado (La Pensée Sauvage, Argentina, 1991).

[78] F.L.A. Pena, Revista Brasileira de Ensino de Física 28, 1 (2006). 